\title{
Seismic Response to hydraulic fracturing in caving mines
}

\author{
D.J. Birch and S.G. Meyer \\ Institute of Mine Seismology, Australia
}

\begin{abstract}
We present qualitative observations of the recorded rock mass response to hydraulicfracturing in four case studies from three major caving mines and demonstrate usefulness in the application of advanced seismological methods to describe this response. Three out of the four cases represent a rare opportunity where the seismic response to hydraulicfracturing was fairly isolated. The activation of structures was readily evidenced using source mechanism analysis. Hydraulic-fracturing applied along the abutment of a cave was shown to be effective in inducing propagation in a highly stressed, stalled section of the cave. The dominant mode of failure in all cases was shear. The amount and type of volumetric change associated with seismicity was dependent on the proximity of the events to mine voids. Seismic activity rates were estimated to be between 10 and 75 times higher during fluid injection than in the time prior to treatment.
\end{abstract}

\section{INTRODUCTION}

Hydraulic fracturing (HF) is commonly employed in underground block caving mines as a means to precondition the rock mass, thereby improving cavability and reducing the seismic hazard Van As (2000) and Catalan et al (2017). When the pressure of the injected fluid exceeds the sum of the rock strength and in situ minimum principal stress, failure is induced. Failure may be interpreted as tensile (hydraulic fracturing), hydro-shearing (frictional strength on a pre-existing plane of weakness is exceeded, inducing slip) or a combination of both where a new fracture is created and then slips as a result of shear stress acting on the plane Gischig and Preisig (2015). The end result is an increase in fragmentation which reduces the capacity of the rock mass to accumulate strain energy, thereby, reducing seismic hazard.

Mines need to evaluate the effectiveness of preconditioning methods and often rely on production figures such as draw rates, rock fragmentation, and percentage of hang-ups, for quantification, i.e., when the rock is mined through, or look to numerical models to provide answers. Modelling the effect of hydraulic fracturing in the rock mass remains inherently troublesome due to necessary assumptions about the medium, in situ stress field, fluid interaction and mode of failure. A thorough analysis of the immediate recorded seismic response to HF is also useful in determining effectiveness and can be performed directly after treatment. Seismological tools such as advanced location methods and the analysis of source parameters and mechanisms can be used to interpret the response in terms of the mode of failure, assess changes in the rock mass properties and stress field and finally, reevaluate the effect on seismic hazard. 
HF logs from four different campaigns (provided by the respective cave mining operations) were analysed in conjunction with the recorded seismic response which varied depending on the sensitivity of the seismic network and rock mass conditions. Information about the individual HF treatments varied from only summary information, i.e., location of the injection point and volume injected, to time history borehole logging for individual fracs. At two of the mines the method was applied on a trial basis and at the third, HF was applied to precondition the rock mass, thereby mitigating severe strain bursting which affected the development of two tunnels in different parts of the mine Rojas and Landeros (2017). This study represents a rare opportunity where the seismic response to HF was fairly isolated, i.e., no production mining taking place nearby, in three out of the four cases. Table I summarises each case. The seismic event magnitude scale is the Hanks and Kanamori (1979) moment magnitude scale denoted by $\mathrm{M}_{\mathrm{HK}}$. The number of events is shown in Table II.

Table I. Summary of hydraulic fracturing campaigns from three different caving mine operations

\begin{tabular}{|c|c|c|c|c|}
\hline Case Study & $\begin{array}{c}\text { Number of } \\
\text { boreholes }\end{array}$ & $\begin{array}{c}\text { Number of injection } \\
\text { episodes }\end{array}$ & $\begin{array}{c}\text { Average volume of fluid } \\
\text { injected per frac }(\mathrm{kL})\end{array}$ & $\begin{array}{c}\text { Magnitude range of recorded seismic } \\
\text { events (MнK) }\end{array}$ \\
\hline 1 & 1 & 13 & 11.21 & -2.3 to -0.1 \\
\hline 2 & 3 & 92 & 16.13 & -1.8 to 0.8 \\
\hline 3 & 7 & 297 & 10.15 & -3.5 to 1.5 \\
\hline 4 & 12 & 505 & Not provided & -2.8 to 1.1 \\
\hline
\end{tabular}

\section{METHOD}

There is a vast difference in the scale of the individual case studies; however, each case was treated similarly from a seismological perspective.

\section{DATA QUALITY CONTROL}

Ground motion resulting from the sudden inelastic deformation related to HF was recorded by each mine's microseismic monitoring network. These networks mostly used $14 \mathrm{~Hz}$ and $4.5 \mathrm{~Hz}$ geophones. The events were selected based on their spatial and temporal association with episodes of HF. The initial phase of the analysis involves accurate calculation of locations and source parameters of events attributed to HF. This is achieved by correctly establishing site settings across the microseismic network and then batch reprocessing the data set. In each case study a controlled database of blasts with known locations was used to derive an appropriate velocity model in the volume of rock mass where HF took place and to confirm the correct sensor orientation settings.

In some cases where large impedance contrasts exist, it was necessary to establish site specific velocities. Relative location, also known as the Arrival Time Difference method or master event location Mendecki (1997), proved useful in cases where the depths of events and seismic wave velocities varied significantly. In a solid rock mass, the first arriving P-waves are polarised in a direction parallel to the direction of propagation at the geophone. This information can be used to further constrain the locations of events by minimising the misfit between the measured polarity of the P-wave at each site (assuming correct orientation settings were established and ray paths are straight) and the current source location.

Figure 1 shows an example where the relative location algorithm was applied. The relocated events (blue spheres) are more clustered and there is a stronger association with an interpolated shape of the yield zone of the cave (grey mesh). The circled events were located using sensors that formed a planar configuration, resulting in the initial location algorithm finding a local minimum. First arrival polarities confirmed that these events occurred closer to the cave and relative location corrected this. 
Quality control of source parameters is conducted by calculating the difference between the observed and theoretical source displacement spectra at each site for a controlled subset of events. The result should be zero across all frequencies, thus, we are able to invert for the anelastic attenuation factors (constant $Q_{\mathrm{P}}$ and $\mathrm{Q}_{\mathrm{s}}$ at frequencies much larger than corner frequency) and identify sites showing severe amplification effects that may be caused by poor grouting in boreholes or damaged sensors and/or cables. Problematic sites were removed from subsequent source calculations.

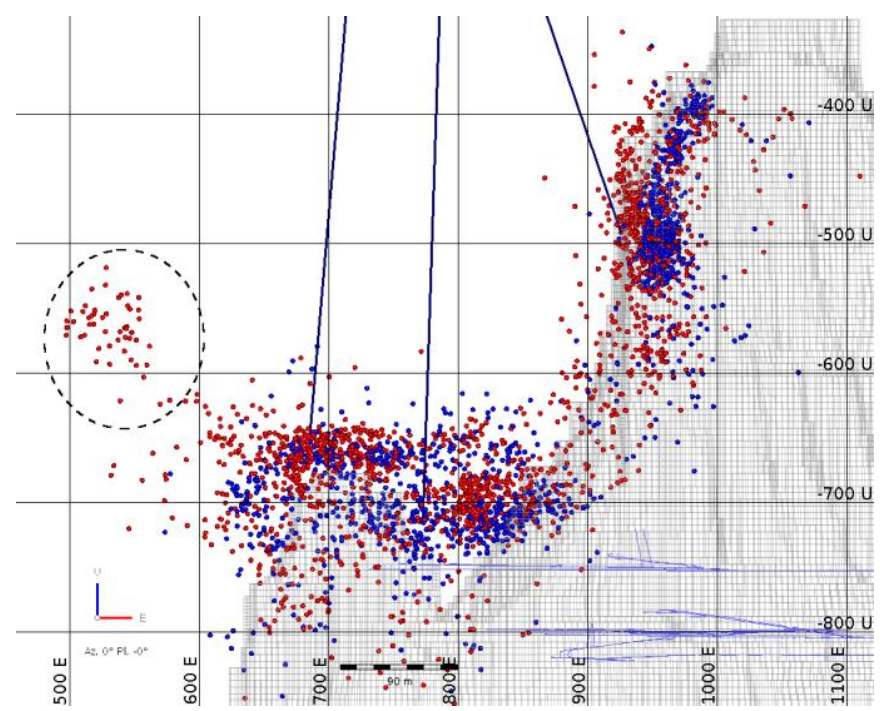

Figure 1. Result of the relative location algorithm applied to HF-induced events along a cave back (Case 2). Red spheres are the original locations and the blue spheres are the relocated events. Blue lines represent the treatment boreholes

\section{SOURCE MECHANISM ANALYSIS}

Following reprocessing of the database of HF related events, the source mechanisms were calculated using a source mechanism inversion method which inverts for the mechanism that provides the best agreement to the observed polarities and amplitudes of $\mathrm{P}$ - and S-waves at trusted sites. A full moment tensor solution is provided. The data sets include thousands of events, which necessitates an automated approach to the calculation. Therefore, selection criteria based on the minimum number of usable Pand S-wave arrivals and focal sphere coverage are used to ensure reliable results.

Results from the application of this method in each of the four case studies are summarised in Table II. The minimum requirements for a source mechanism included; $6 \mathrm{P}$-wave arrivals, $6 \mathrm{~S}$-wave arrivals and a minimum focal sphere coverage of $50 \%$.

Table 2. Total number of full moment tensor calculations carried out for each case study

\begin{tabular}{|c|c|c|c|}
\hline Case study & Number of HF-related events & Number of full moment tensor solutions & Percentage successful calculations \\
\hline 1 & 2064 & 704 & $34 \%$ \\
\hline 2 & 1233 & 251 & $20 \%$ \\
\hline 3 & 8519 & 1737 & $20 \%$ \\
\hline 4 & 2636 & 518 & $20 \%$ \\
\hline
\end{tabular}


The interpretation of HF-induced seismic events focuses on all aspects of the full moment tensor solution and makes inferences about the mode of failure and changes in the stress field, and possibly identifies structures which may have failed suddenly. These aspects include:

i. directions of the principal strain axes

ii. amount of constant-volume shear vs. volumetric change

iii. nodal planes.

The directions of the maximum and minimum principal strain axes are proxies for the directions of principal stress in the rock mass driving sudden inelastic deformation at a particular location and point in time. The T-axes (direction of minimum principal strain) indicate extension while P-axes (direction of maximum principal strain) indicate compression. This information can be visualised in 3D to provide an indication of how the stress field is oriented in the volume.

Hudson plots Hudson (1989), also referred to as source-type plots, display the range of the obtained moment tensor types in terms of two parameters $T$ and $k$, which characterise the relative amounts of shearing (deviatoric component of the full moment tensor) and volumetric change (isotropic component of the full moment tensor), respectively. These plots provide a generalised overview of the dominant source-type/mode of failure. It is common to see a number of events with large volumetric change components inwards (implosive). This can be attributed to elastic convergence in nearby excavations.

Source mechanisms and event locations can easily be compared with the spatial distribution of mapped geological structures but often unknown structures are illuminated by the HF. Clusters of events with significant double-couple components can potentially be attributed to slip on a geological structure if the distribution of the events is found to be co-planar with one of the nodal planes of the source mechanisms of the events in question.

\section{RESULTS}

The case studies and corresponding results are described individually. It is important to keep in mind that Case 2 was the only case study where HF was applied in the yield zone of an established cave.

\section{Case 1}

Kiruna mine, Sweden

A HF trial was conducted in a single borehole involving 13 fracs. The borehole was located between two mining blocks far from the cave. The microseismic monitoring array provided excellent coverage with a high level of sensitivity. This is reflected in the high number of events relative to the number of fracs and high success rate of moment tensor solutions (See Tables I and II). The relative location method was applied to the event set. Figure 2 suggests that a correlation exists between the amount of fluid injected, range of spatial distribution of recorded events and number of recorded events.

The calculation of seismic source mechanisms produced a large majority of predominantly doublecouple (shearing) type events (See Figure 3). A high number of planar clusters were identified. These were characteristically varied in terms of the planar distribution of locations relative to the associated seismic source mechanisms. In certain clusters (See Figure 2) the planar distribution of event locations or event planes are aligned with a common nodal plane from the mechanism solutions, indicating slip along an existing plane of weakness. In other groups the strike of the event plane was sub-parallel to the P-axes ( $\sim 45^{\circ}$ offset from the nodal planes). This is not fully understood but one possibility is shear slip along parallel joints brought about by perturbations in the stress field during fluid injection.

Size distributions of two event sets (Normalised to 30 days) are compared in Figure 4 . The events were recorded in the months before hydraulic-fracturing and during fluid injection in the same volume. 
Although the time scales are different, normalisation allows us to compare the activity rates based on a particular magnitude of completeness. A completeness magnitude of $\mathrm{M}_{\min }=-1.2$ is appropriate in this case. The activity rate is approximately 75 times higher during injection. The slope appears to be steeper indicating a higher ratio of small-to-large events.

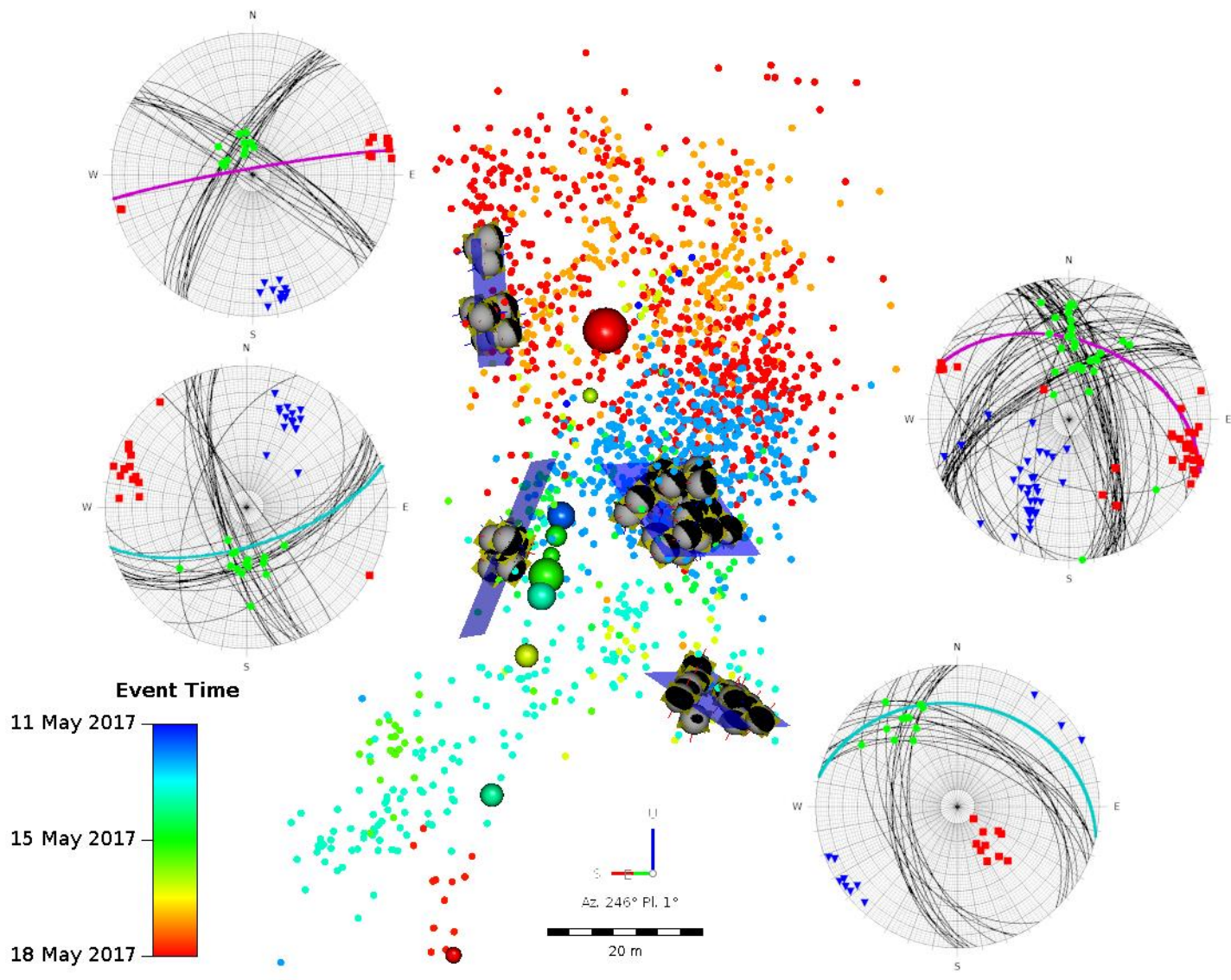

Figure 2. Correlation of event location planes with source mechanism solutions looking NW. The dots represent all recorded events coloured according to time. Spheres represent the injection points scaled according to volume injected and coloured according to time. Stereonets display nodal planes and the $P_{-}, T$ - and B-axes (represented by red, blue and green markers, respectively) of the source mechanism solutions for planar clusters

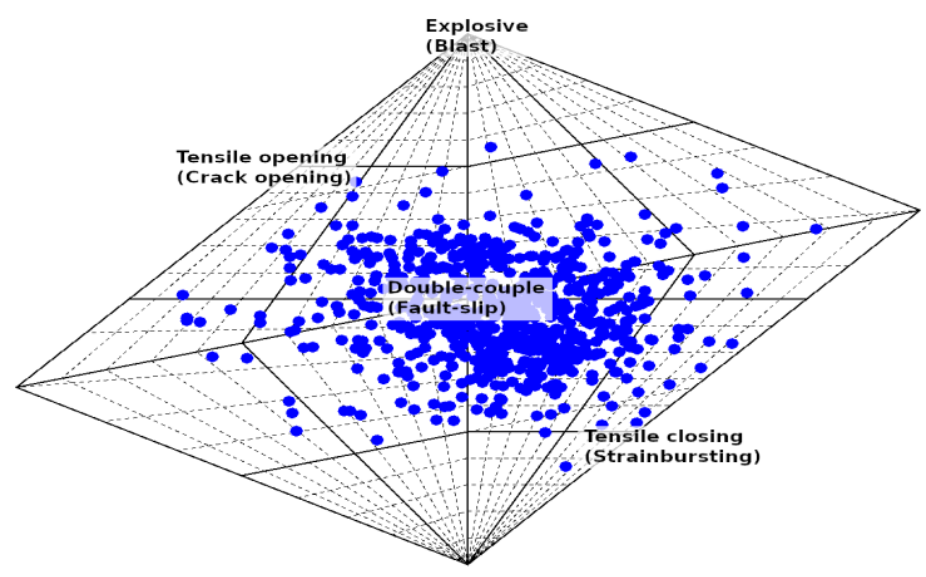

Figure 3. Hudson diagram of source mechanism solutions obtained for HF-induced events for Case 1 


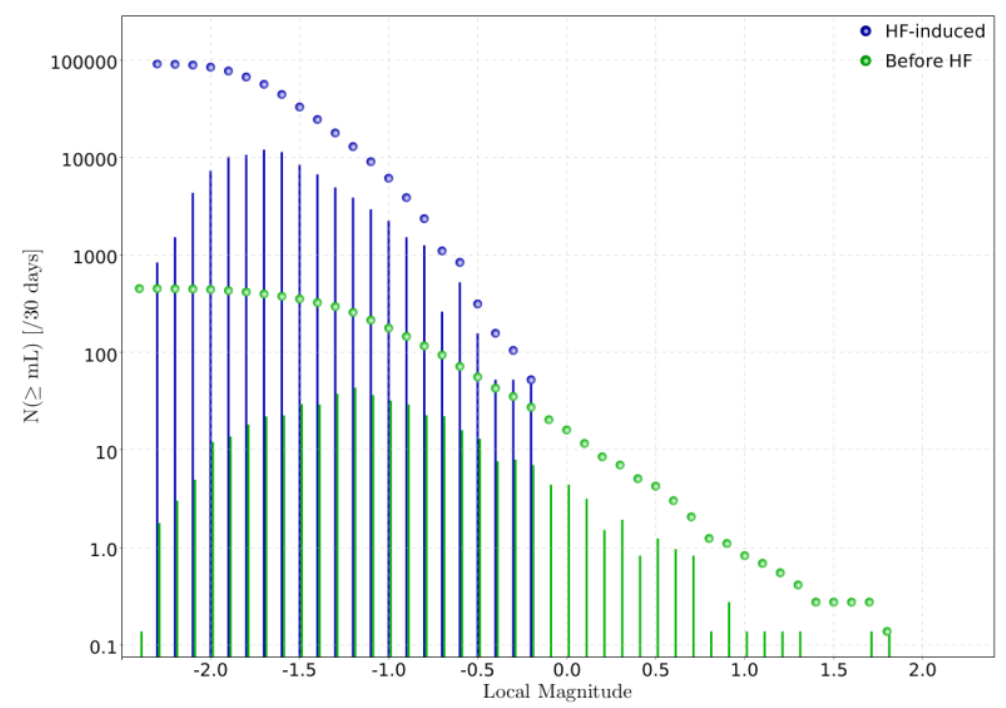

Figure 4. Comparison of normalised cumulative size distribution plots for HF-induced events and events recorded in the same volume prior to HF between Blocks 30 and 34 at Kiruna mine

\section{Case 2}

Malmberget mine, Sweden

Hydraulic fracturing was conducted on a trial basis along the western flank of the Printzsköld cave involving three boreholes drilled from the surface ( $500 \mathrm{~m}$ to $700 \mathrm{~m}$ in depth). The in situ stress conditions and shape of the cave provide favourable conditions for large events that are readily felt on surface. Therefore, a major theme of this trial was to study the effect on cave propagation to re-distribute stress and reduce the seismic hazard. The relocated events are closely associated with the yield zone of the cave. The effect of the yield zone is evident in the HF parameters. Breakdown pressure tends to decrease while volume injected increases as the injection points get nearer the cave. The source mechanisms when plotted on a Hudson diagram (See Figure 5) tend towards tensile closing. This can be explained by closure (failure towards the source) within the yield zone of the cave.

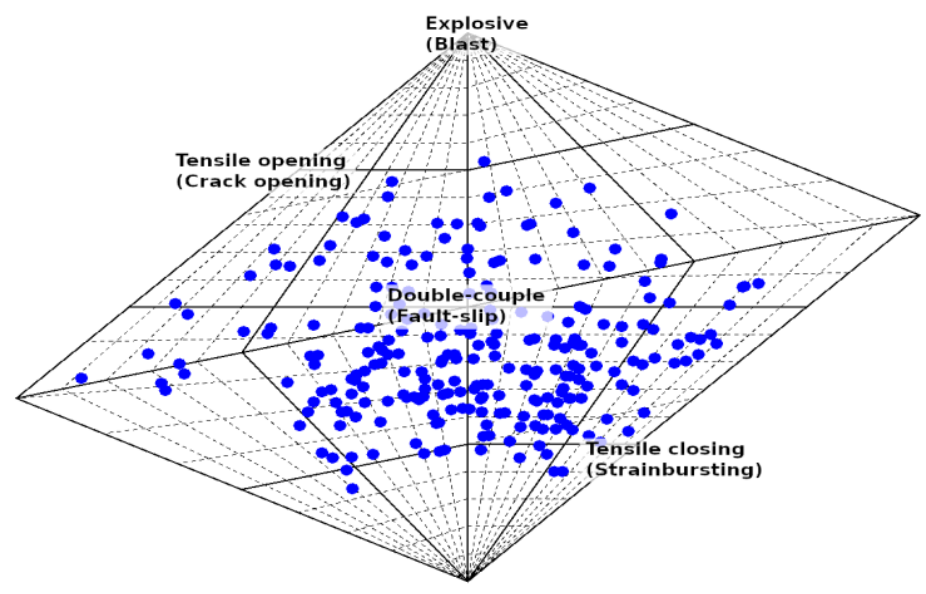

Figure 5. Hudson diagram of source mechanism solutions obtained for HF-induced events along the a cave abutment 
Directions of the principal strain axes obtained in the source mechanism calculations support the notion of cave growth, particularly in the bridge between the two sub-caves. The T-axes (Blue vectors in Figure 6) were predominantly sub-orthogonal to the cave indicating extension. The P-axes (Red vectors in Figure 6) correlate well with the in situ maximum principal stress, which is horizontal and oriented approximately NW-SE.

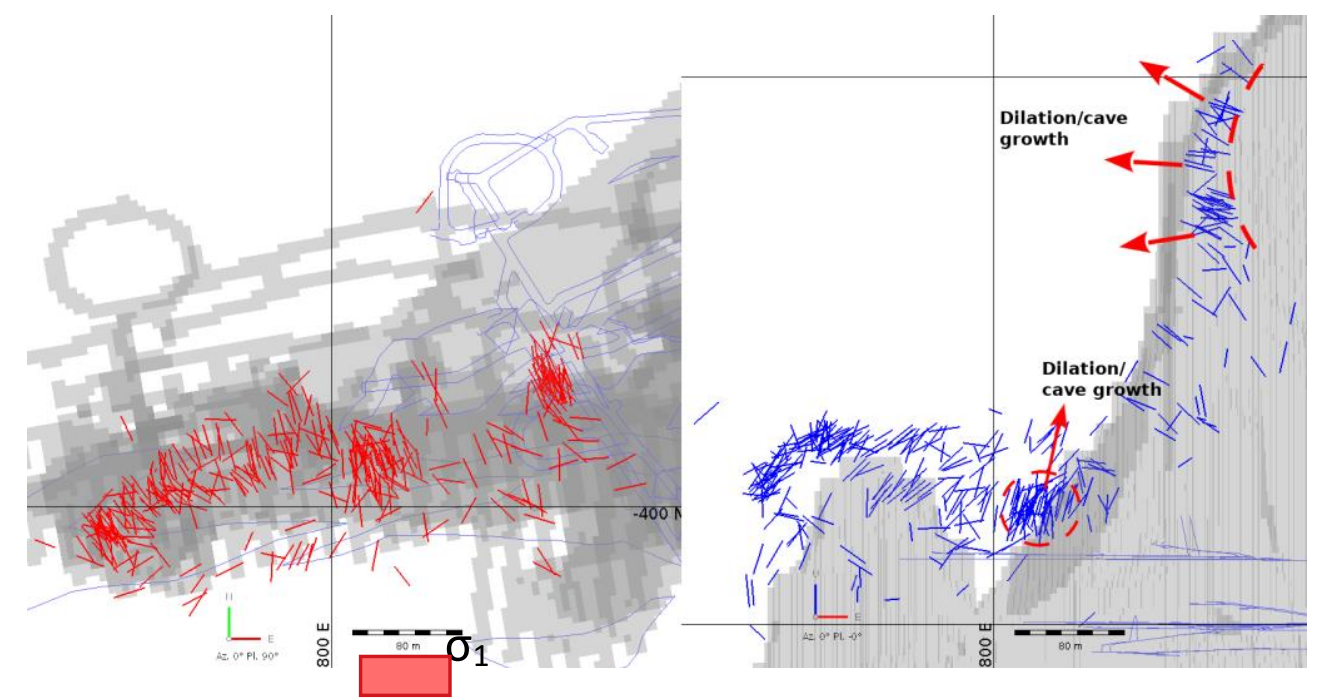

Figure 6. Orientations of P-axes displayed in plan view (left) and T-axes looking North (right) obtained from source mechanisms of events recorded during treatment. Red arrows show the approximate orientation of the in situ maximum principal stress

Comparing the spatial distribution of events in the two months before, during and after treatment (See Figure 7) shows how HF altered the shape of the seismogenic volume around the cave in the short term. The zone around the deeper sub-cave was responsible for most of the recorded activity prior to HF as a result of stress concentration in a stalled section (bridge). After treatment, however, the event clusters shifted, smoothing over this section and associating with the yield zone of the larger, more established cave.

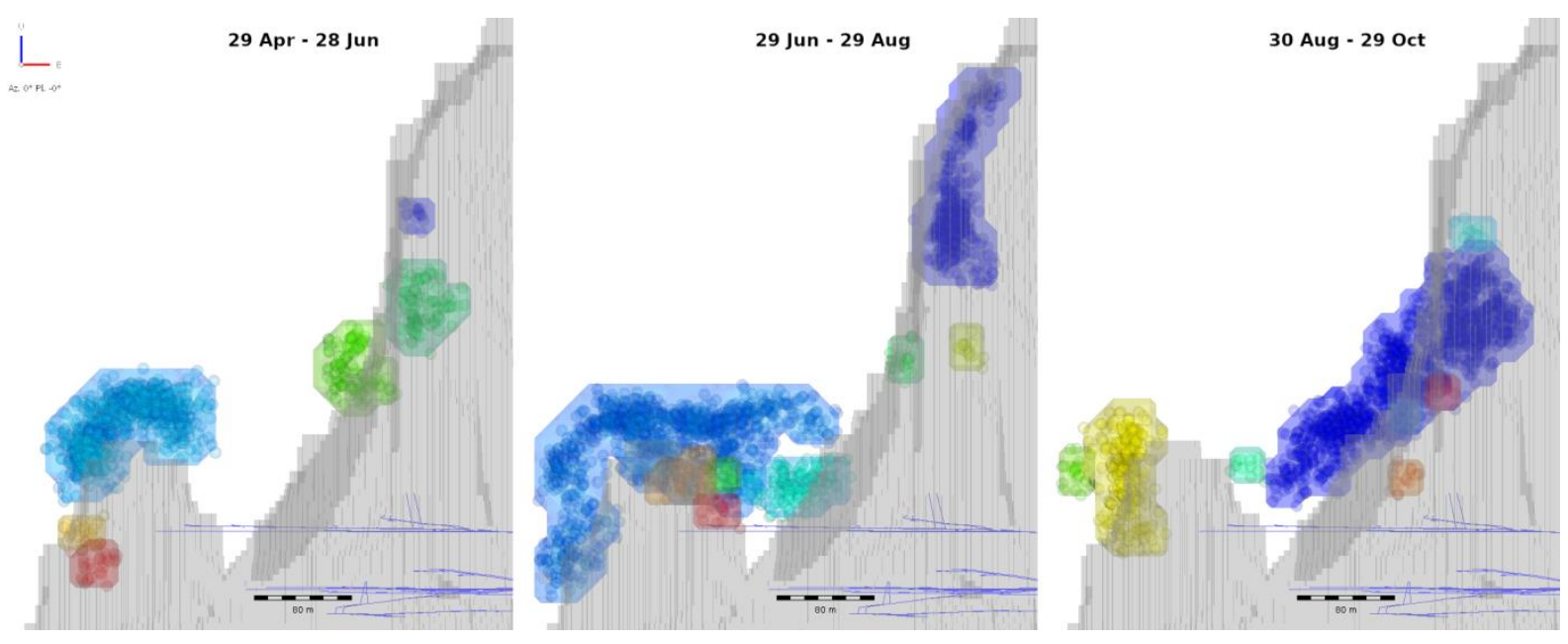

Figure 7. Comparison of event density clusters before, during and after HF treatment along the cave abutment

A comparison of the size distributions of events (normalised to 30 days) recorded 6 months prior to and during fluid injection shows a higher activity rate (approximately 10 times for a minimum magnitude of completeness of $\mathrm{M}_{\mathrm{HK}}-1.1$ ), a higher proportion of smaller magnitude events and a smaller maximum 
recorded magnitude (See Figure 8). This supports the notion that there is a reduction in the accumulation of strain energy through an increase in fragmentation.

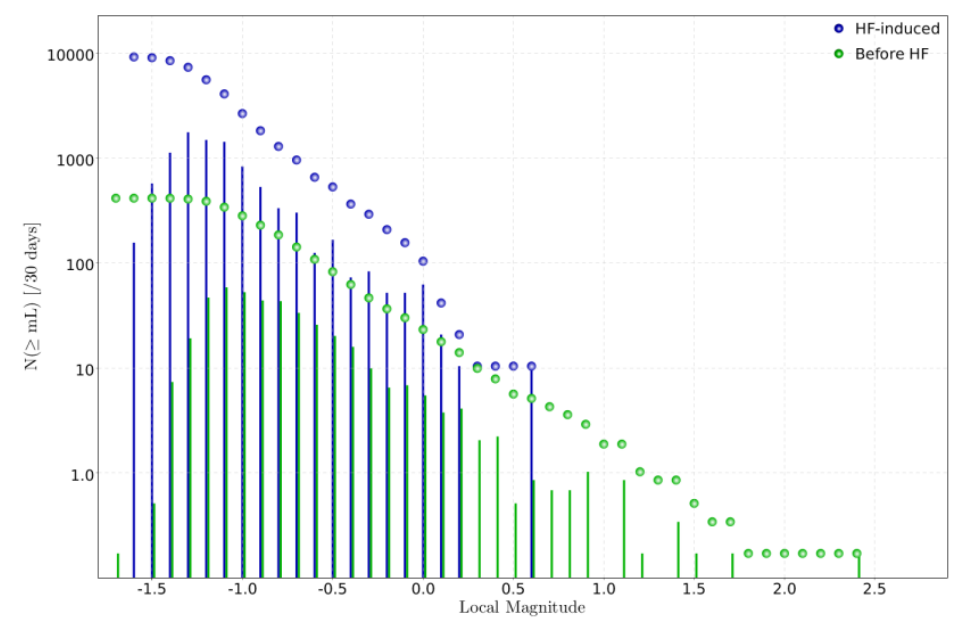

Figure 8. Comparison of normalised cumulative size distribution plots for HF-induced events and events recorded in the same volume prior to HF along the Printzsköld cave at Malmberget mine

\section{Case 3}

Personnel access tunnel El-Teniente mine, Chile

HF is common practice at El-Teniente mine, being applied regularly to improve production during block caving through increased fragmentation as well as reduce hazard around the working levels. This case fell into the latter of the two uses - to precondition the rock mass for the development of a tunnel with the aim of reducing the number of damaging strain bursts Rojas and Landeros (2017). Treatment boreholes were drilled on either side of approximately $120 \mathrm{~m}$ of planned tunnel.

Development of the tunnel had already started prior to HF. Treatment started $20-50 \mathrm{~m}$ from the end of the tunnel moving away in the direction of planned tunnelling. As a result, the first fracs generated a large seismic response around the tunnel end. P-axes from source mechanisms in this cluster are subparallel to the excavation suggesting that deformation was driven by tunnel-induced stresses (See Figure 9). It is, therefore, reasonable to conclude that HF successfully redistributed stress in this volume. The majority of source mechanisms are classified as shear slip (See Figure 10). A large planar distribution of events was visible after relocation. Source mechanism analysis showed agreement with one of the nodal planes in this cluster and the event plane (See Figure 11). The tunnel had not yet intersected this plane.

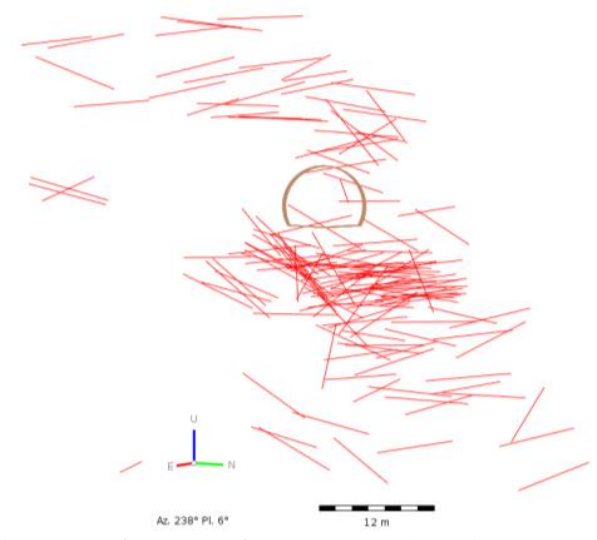

Figure 9. Distribution of P-axes from HF-induced events around the tunnel 


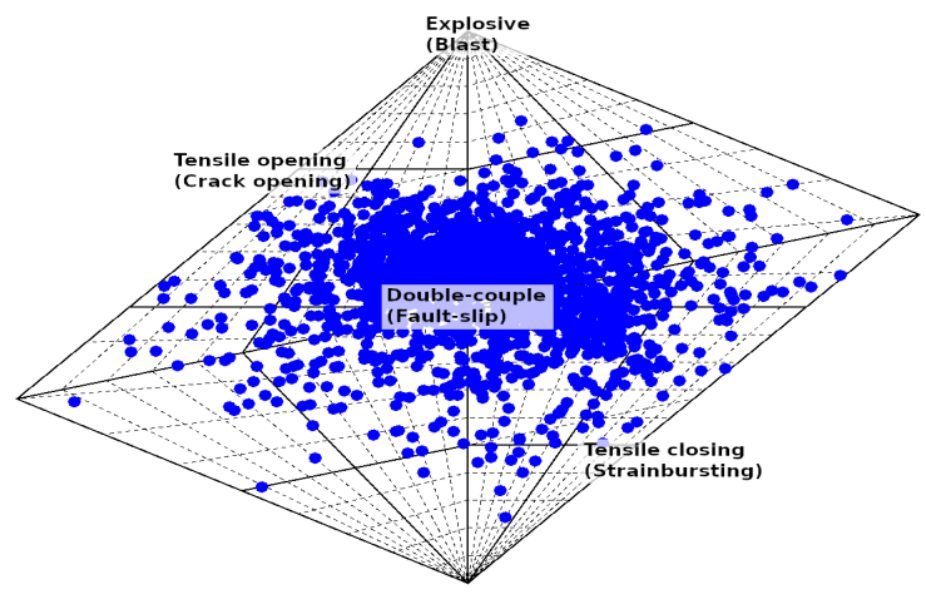

Figure 10. Hudson diagram of source mechanism solutions obtained for HF-induced events at TAP

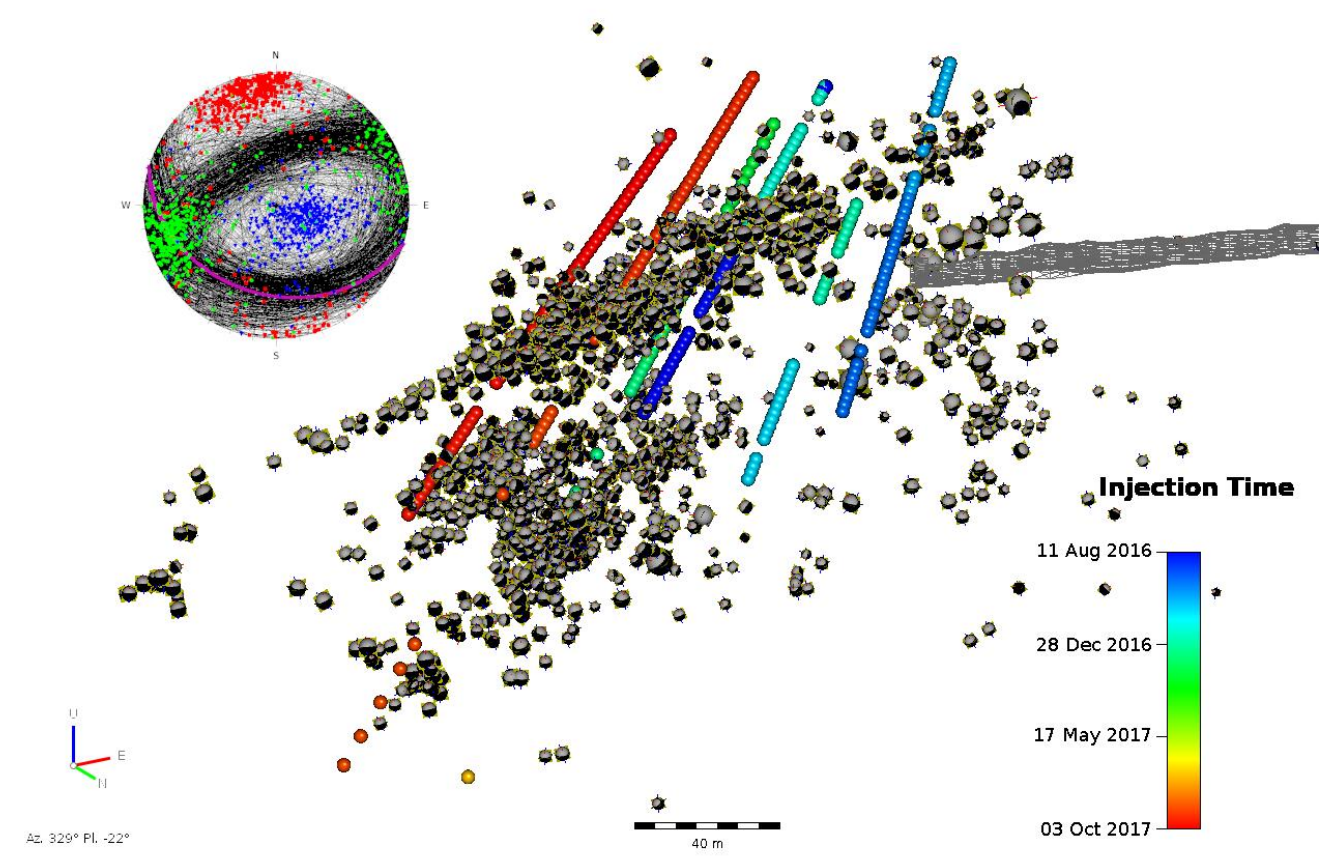

Figure 11. Activation of a structure by HF ahead of the tunnel. Spheres mark the injection points and are coloured according to time. Nodal planes and poles of the principal strain axes from the selected events (circled) are projected onto the stereonet (insert)

A comparison of the size distributions of events recorded prior to HF versus events induced by HF in the same volume is presented in Figure 12. A longer time window (3 years) was required to sample the volume before HF compared to Case 1 and 2. During this time the majority of events were related to blasting (early development of the TAP tunnel) and had a larger completeness magnitude due to a lower system sensitivity at the time. For $\mathrm{M}_{\min }-0.4$, the activity rate is approximately 30 times higher during fluid injection. The slopes in the size distributions are similar, unlike Case 1 and 2 where a steeper slope was observed during HF. However, the maximum recorded magnitude during HF was also lower in this case. 


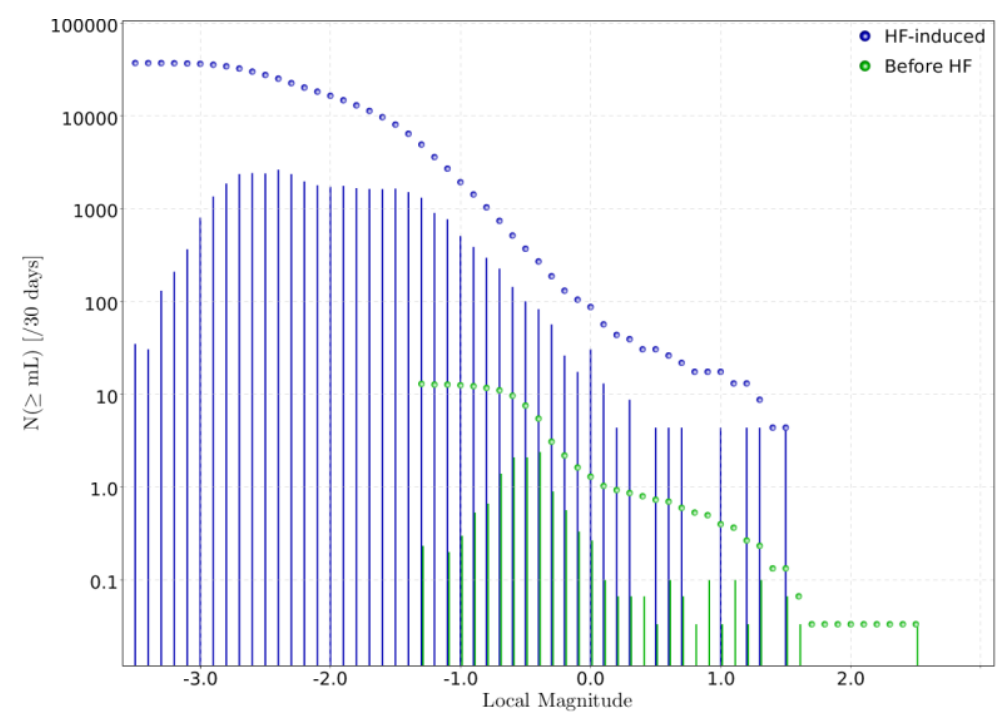

Figure 12. Comparison of normalised cumulative size distribution plots for HF-induced events and events recorded in the same volume prior to HF around the TAP tunnel, El-Teniente mine

\section{Case 4}

XC-22/23 tunnel El-Teniente mine, Chile

This scenario was similar to Case 3, only on a larger scale, and is also discussed by Rojas and Landeros (2017). HF spanned a section, approximately $340 \mathrm{~m}$ long, trending east to west, that would later be tunnelled through. Brzovic et al (2017) reported that the implementation of HF resulted in an increased rate of seismic activity in the area and a lower range of magnitudes. The relocated events showed a large horizontal spatial extent to the north and south of the treatment boreholes. It is likely that this diffusion was aided by existing geological structures and driven by the in situ maximum principal stress, which is sub-horizontal and oriented approximately NNW-SSE (See Figure 13). There was good agreement between the orientation of $\sigma_{1}$ and P-axes from the mechanism solutions. The T-axes are mostly subvertical. The majority of seismic source mechanisms were double-couple (See Figure 14). Evidence of shallow-dipping, sub-parallel structures was found (See Figure 15).

As was observed in Case 3 (TAP), events recorded in the volume prior to HF were scarce. There was, however, a history of seismic events related to the development of the tunnel. A comparison of the cumulative size distributions (See Figure 16) yields a similar result. The total injection duration had to be approximated due to incomplete information. An average injection duration calculated form partially complete information at TAP was assumed and used in the normalisation of the size distribution for HF-induced events at XC-22/23. It is reasonable to assume that the same HF procedure was carried out at both sites. The observations in both cases are similar. Figure 16 shows a higher level of activity ( $\sim 30$ times for $\left.\mathrm{M}_{\min }-0.2\right)$ during HF, similar slopes for both size distributions and a lower maximum recorded magnitude during HF. 


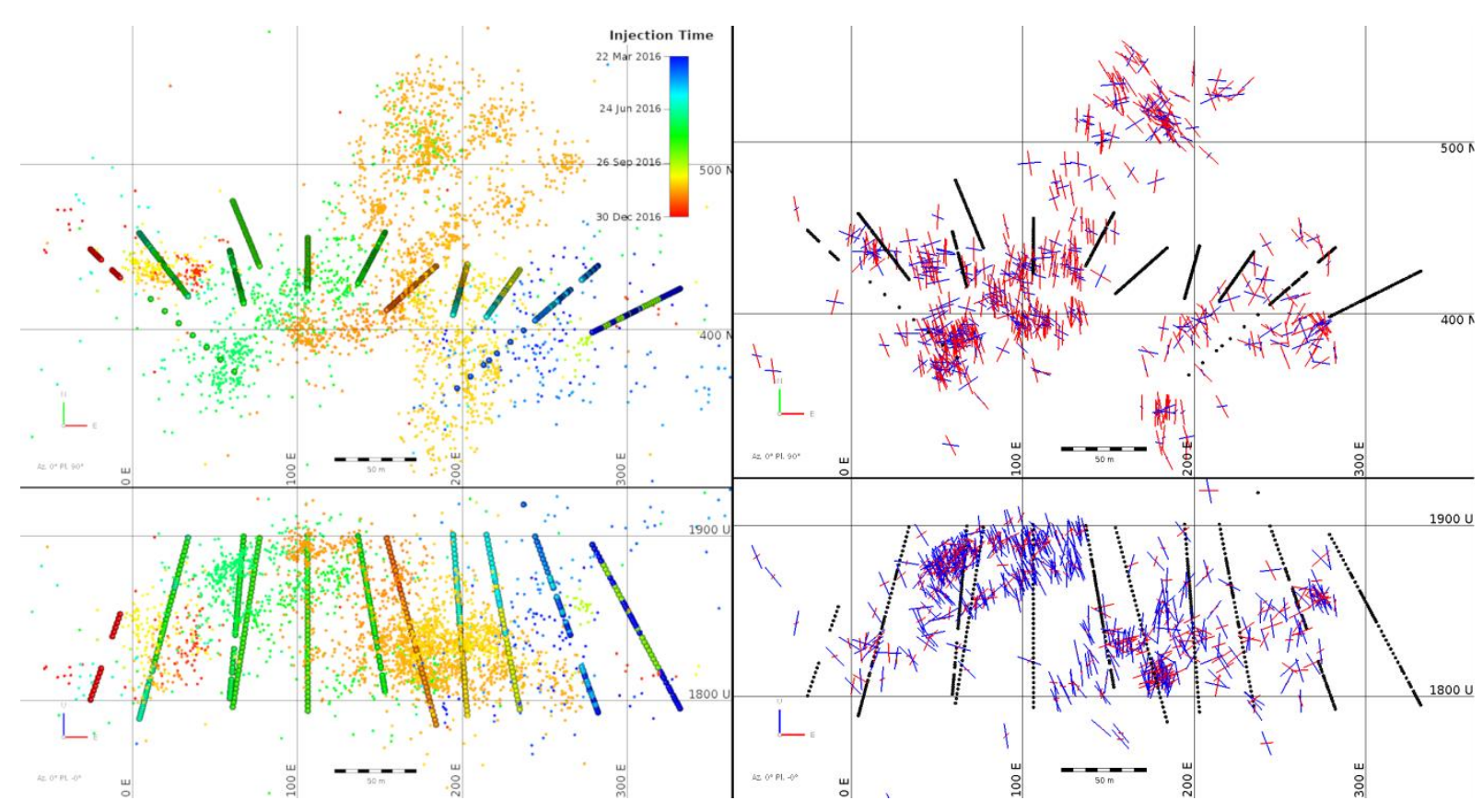

Figure 13 - Distribution of events recorded during HF in plan view (top) and looking north (bottom). The events are coloured according to time (left) and mechanism solutions (right) are represented by maximum and minimum principal axes ( $P$-axes are red and $T$-axes are blue)

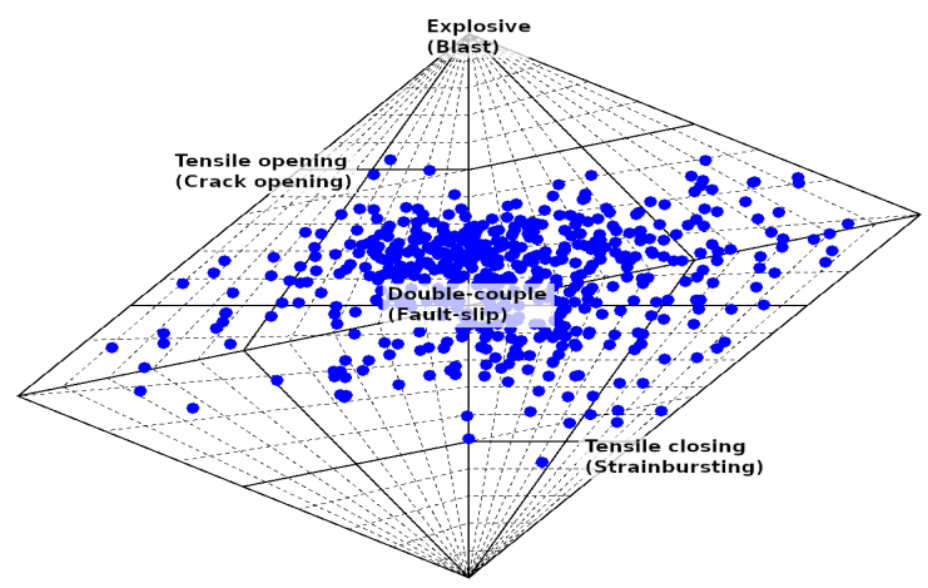

Figure 14. Hudson diagram of source mechanism solutions obtained for HF-induced events at XC-22/23 


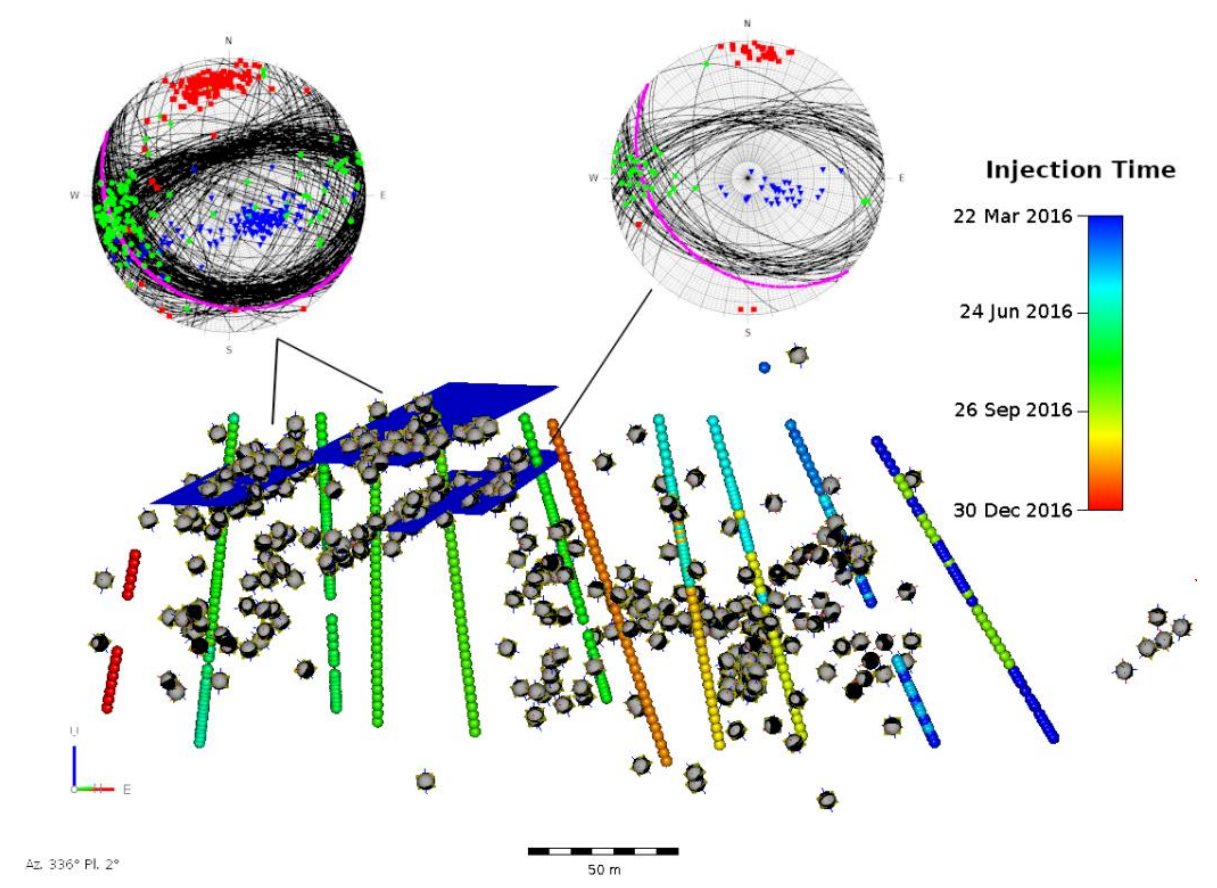

Figure 15. Evidence of shallow-dipping, sub-parallel planes that were active during HF at XC-22/23. Nodal planes and principal strain axes from selected events are projected onto stereonets

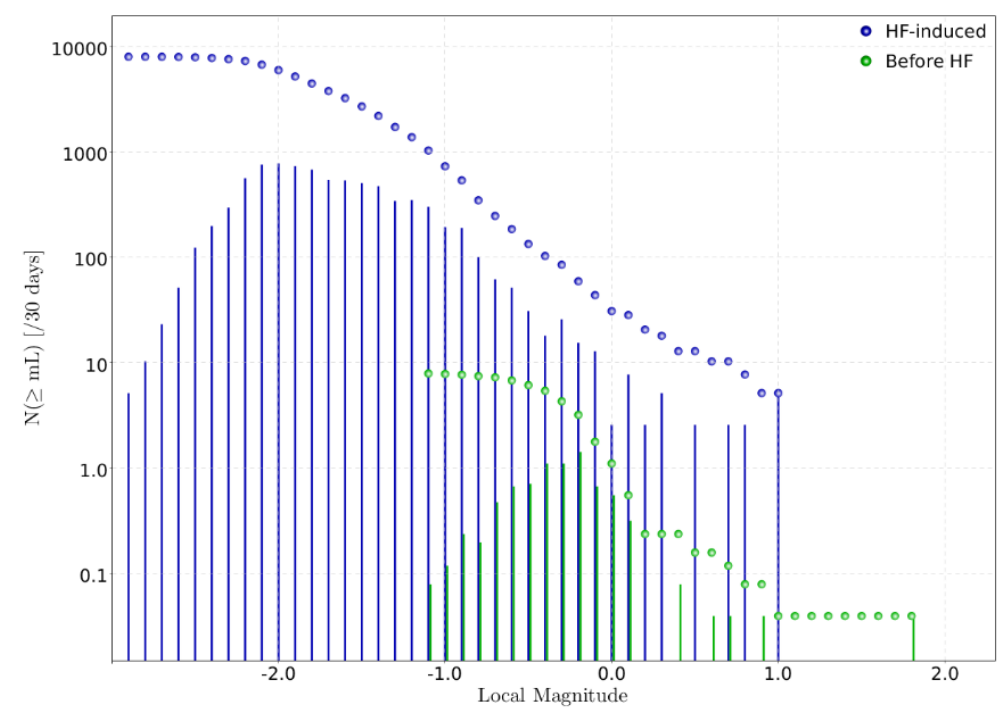

Figure 16. Comparison of normalised cumulative size distribution plots for HF-induced events and events recorded in the same volume prior to HF around the XC-22/23 tunnel, El-Teniente mine 


\section{CONCLUSIONS}

We present qualitative observations of the recorded rock mass response to HF at three major caving mines and demonstrate usefulness in the application of advanced seismological methods to describe this response.

The activation of structures is fairly common and readily evidenced using source mechanism analysis. Curiously, we observed event locations forming planes aligned parallel to the P-axes. A possible explanation for this is slip along parallel joints, not caused directly by fluid, but rather through perturbations in the stress field as a result of fluid injection. One case of treatment applied along the abutment of an established cave (partially within the yield zone) is fairly unique. A key observation in this case was the effectiveness of the method to redistribute stress and propagate the cave in a critical zone, one where large events were being generated as a result of stress concentration. HF was instrumental in reducing the number and severity of damaging strain bursts during the development of two tunnels at El-Teniente mine. At XC-22/23, the effect of local geology and in situ stress resulted in events being recorded at large distances from the injection points ( $>100 \mathrm{~m})$. Unfortunately, this could not be statistically evaluated as it was for the other cases (See Table 3) due to missing information.

Characteristics of the recorded seismic response are summarised in Figure 17 and Table III and provide valuable information on the implications for seismic hazard during fluid injection. Figure 17 is a plot of the distances between individual events triggered during fluid injection with magnitudes above the respective $\mathrm{M}_{\min }$ and injection points. Start and stop times of HF were used to filter the data. The median and standard deviation was calculated for each set of data (See Table 3). The spatial extent of the recorded response in Case 2 (Malmberget) was significantly larger than the rest. This can be attributed to the proximity of the cave yield zone.

Dominant source types were estimated by taking the mean of the parameters $k$ (Volumetric change) and $T$ (constant-volume shear). The values are given in Table III and plotted in Figure 18. Results suggest that the observed mode of failure in all cases was predominantly shear. Cases 3 and 4 showed slightly more explosive mechanisms. Case 2 was the most implosive of them all. This was expected due to the proximity of the events to the cave.

Increases in the activity rates during fluid injection were estimated from size distribution plots (normalised to 30 days) of events recorded during fluid injection and prior to HF in the same volume. Completeness magnitude between the event set pairs varied as system sensitivity had, in most cases improved by the time HF started. In all cases, the maximum recorded magnitude during HF is lower while the activity rates are between 10 and 75 times higher.

Table III. Characteristics of the recorded seismic response to HF in deep caving mines

\begin{tabular}{|c|c|c|c|c|c|}
\hline $\begin{array}{c}\text { Case } \\
\text { study }\end{array}$ & $\begin{array}{c}\text { Dominant } \\
\text { source-type } \\
\text { mean }(k, T)\end{array}$ & $\begin{array}{c}\text { Spatial range of } \\
\text { recorded response } \\
\text { (median, STDEV) }[\mathrm{m}]\end{array}$ & $\begin{array}{c}\text { Activity rate increase } \\
\text { during fluid injection }\end{array}$ & \multicolumn{2}{|c|}{$\begin{array}{c}\text { Maximum recorded magnitude (MHK) } \\
\text { Before HF } \\
\text { During HF }\end{array}$} \\
\hline 1 & $-0.049,0.112$, & 26,10 & $\sim 75$ times $\left(\mathrm{M}_{\min }-1.2\right)$ & 1.8 & -0.1 \\
\hline 2 & $-0.150,0.039$ & 55,57 & $\sim 10$ times $\left(\mathrm{M}_{\min }-1.1\right)$ & 2.4 & 0.8 \\
\hline 3 & $0.077,0.041$ & 48,28 & $\sim 30$ times $\left(\mathrm{M}_{\min }-0.4\right)$ & 2.6 & 1.5 \\
\hline 4 & $0.088,0.103$ &,-- & $\sim 30$ times $\left(\mathrm{M}_{\min }-0.2\right)$ & 1.9 & 1.1 \\
\hline
\end{tabular}




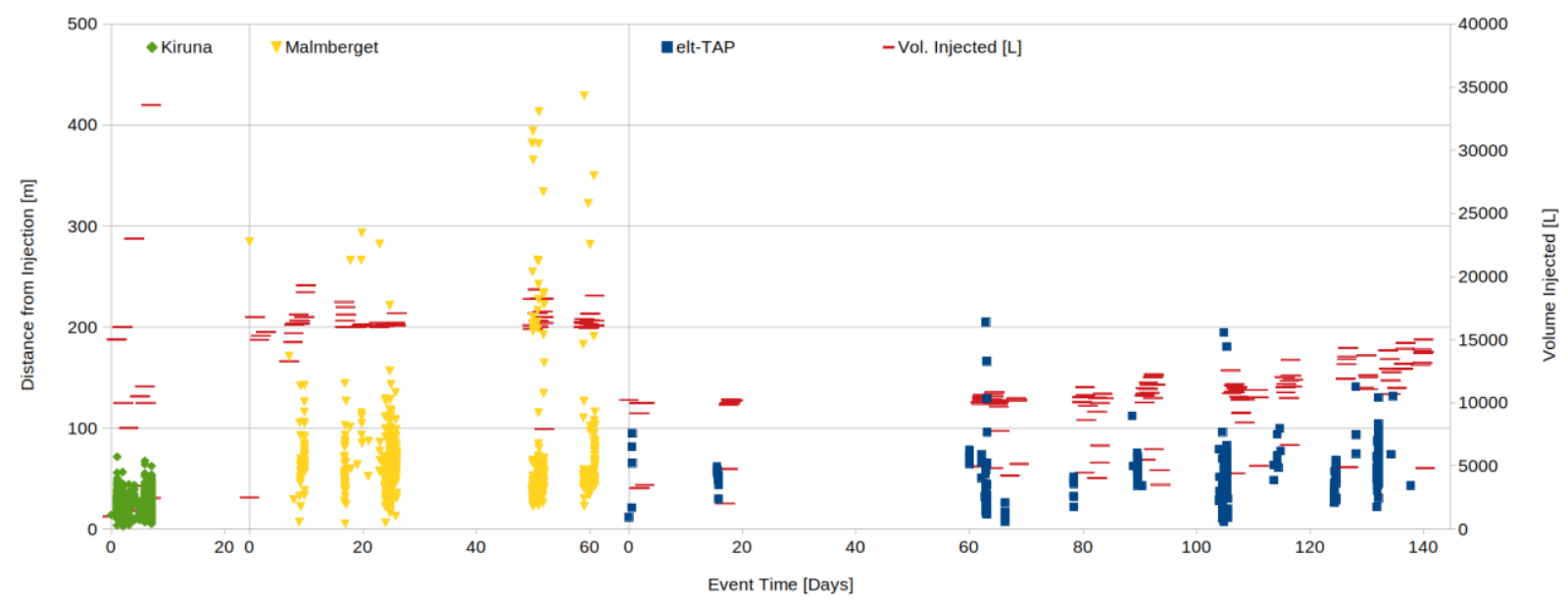

Figure 17. Concatenated distance versus time plot of the observed seismic response during HF

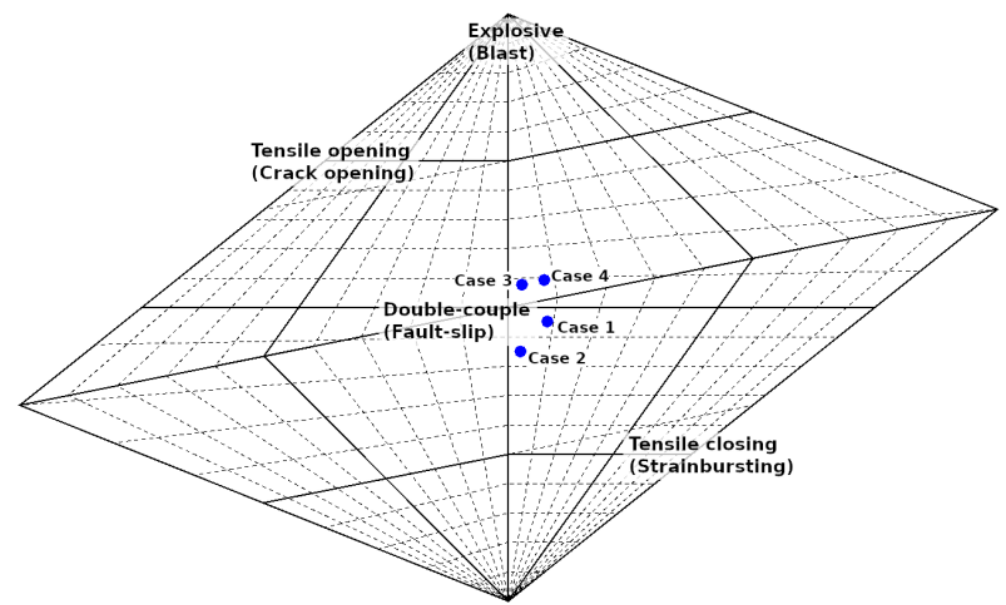

Figure 18. Dominant source types represented by mean values of $k$ and $T$ from moment tensor solutions of HFinduced events in each case displayed on a Hudson source-type plot 


\section{REFERENCES}

Brzovic, A., Skarmeta, J., Blanco, B., Dunlop, R. and Sepulveda, M.P. (2017). Sub-horizontal faulting mechanism for large rock bursts at the El-Teniente mine. Proceedings of the $9^{\text {th }}$ International Symposium on Rockbursts and Seismicity in Mines. Vallejos, J.A. (ed). Santiago, Chile. pp. 124-132.

Catalan A., Onederra, I. and Chitombo, G. (2017). Evaluation of intensive preconditioning in block and panel caving - part II, quantifying the effect on seismicity and draw rates. Mining Technology, DOI: 10.1080/14749009.2017.1319527.

Gischig, V.S. and Preisig, G. (2015). Hydro-fracturing versus hydro-shearing: A critical assessment of two distinct reservoir stimulation mechanisms. Proceedings of the $13^{\text {th }}$ International Congress of Rock Mechanics. ISRM, Montréal, Canada.

Hanks, T. C. and Kanamori, H. (1979). A moment magnitude scale. Journal of Geophysical Research, 84 (5), pp. 2348-2350.

Hudson, J., Pearce, R. and Rogers, R. (1989). Source Type plot for inversion of the moment tensor. Journal of Geophysical Research, 94(B1), 765-774.

Mendecki, A. J. (1997). Seismic Monitoring in Mines. Chapman and Hall, Cambridge.

Rojas, E. and Landeros, P. (2017). Hydraulic fracturing applied to tunnels development at El-Teniente mine. Proceedings of the $9^{\text {th }}$ International Symposium on Rockbursts and Seismicity in Mines. Vallejos, J.A. (ed). Santiago, Chile. pp. 244-250.

Van As, A. and Jeffrey, R.G. (2000). Hydraulic fracturing as a cave inducement technique at NorthParkes Mines. Proceedings of MassMin 2000. Mang, H.A., Rammerstorfer, F.G. and Eberhardsteiner, J. (eds). AusIMM, Brisbane, Queensland. pp. 165-172. 


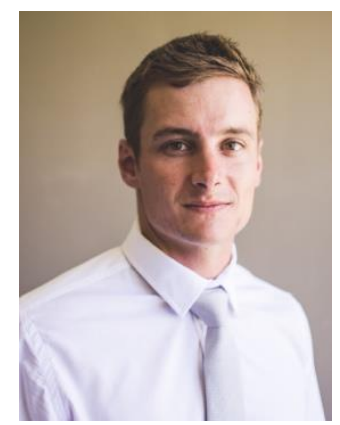

\section{Denver Julian Birch}

Mine Seismologist

Institue of Mine Seismology

Denver is a Mine Seismologist for the Institute of Mine Seismology in Hobart, Australia. He began his career as a Junior Scientist at the Council for Geoscience, South Africa in 2009 where his work included studies on site response, seismic disturbances in residential areas, seismic wave attenuation and modelling fluid-induced seismicity. In 2013 he graduated Cum Laude with a Master of Science degree from the University of Pretoria Department of Physics and in 2017 joined the Institute of Mine Seismology. Denver has since been providing routine and advanced seismological services to the mining industry with a focus on rock mass response to hydraulic fracturing in underground mines. 